\title{
Glycerol Metabolism and Triglyceride-Fatty Acid Cycling in the Human Newborn: Effect of Maternal Diabetes and Intrauterine Growth Retardation
}

\author{
DEEPAK PATEL AND SATISH KALHAN \\ Department of Pediatrics, Case Western Reserve University School of Medicine, Cleveland, Ohio 44I06
}

\begin{abstract}
Kinetics of glycerol metabolism and triglyceride/fatty acid cycling were quantified in 12 healthy, normal, appropriate-for-gestational-age (AGA) infants, eight small-for-gestational-age (SGA) infants, and five infants of insulin-dependent diabetic mothers (IDM) at less than $48 \mathrm{~h}$ of age. Stable isotope-labeled $\left[2-{ }^{13} \mathrm{C}\right]$ glycerol and $[6,6-$ ${ }^{2} \mathbf{H}_{2}$ glucose in combination with indirect respiratory calorimetry were used. The tracers were used as constant rate infusion and steady state isotopic enrichment of glucose, glycerol, and bicarbonate was measured by mass spectrometric methods. After a 7- to 9-h fast, the plasma glucose, glycerol, and FFA concentrations were similar in the AGA and IDM groups. In the SGA group, the plasma glucose concentration was significantly lower than that in the AGA group throughout the study, but plasma FFA and glycerol concentrations were not different from those in the AGA infants. Plasma betahydroxybutyrate concentration was significantly elevated in the AGA group compared with IDM and SGA infants (AGA 0.59 \pm 0.39 , SGA $0.35 \pm 0.09$, IDM $0.33 \pm 0.21 \mathrm{mmol} / \mathrm{L} ;$ mean $\pm \mathrm{SD})$. The rate of appearance of glycerol was significantly elevated ( $p$ $<0.05$ ) in SGA infants (AGA 9.47 \pm 2.11 , IDM 9.55 \pm 2.14, SGA $12.15 \pm 3.87 \mu \mathrm{mol} / \mathrm{kg} \cdot \mathrm{min})$. Between 80 and $90 \%$ of glycerol turnover was converted to glucose, accounting for $20 \%$ of glucose turnover with no significant difference in the three groups. Approximately $35 \%$ of glycerol carbon was recovered in the bicarbonate $\left(\mathrm{CO}_{2}\right)$ pool. Less than $5 \%$ of $\mathrm{CO}_{2}$ carbon was derived from glycerol. Estimation of triglyceride-fatty acid cycle revealed that the triglyceride energy mobilized was increased in SGA infants. Only $22-24 \%$ of the triglyceride energy released was oxidized to $\mathrm{CO}_{2}$ in the newborn infants; the majority (76$78 \%$ ) was recycled back to the adipose tissue. These data show that lipolysis is active in the immediate neonatal period. The contribution of fat to oxidative metabolism is increased in SGA infants. The major metabolic fate of glycerol in the neonate is conversion to glucose, and glycerol is a minor contributor to oxidative metabolism. (Pediatr Res 31: 52-58, 1992)
\end{abstract}

\section{Abbreviations}

AGA, appropriate for gestational age SGA, small for gestational age IDM, infant of diabetic mother

Received June 14, 1991; accepted August 1, 1991

Correspondence: Satish Kalhan, M.D. Division of Neonatology, Rainbow Babies and Children's Hospital, 2101 Adelbert Road, Cleveland, OH 44106.

Supported by the Perinatal Emphasis Research Center Grant HD 11089 from the National Institute of Child Health and Human Development and Clinical Research Center Grant RR00210 from the National Institutes of Health.

\author{
GC-MS, gas chromatograph-mass spectrometer \\ $\mathrm{V}_{2}, \mathrm{O}_{2}$ consumption \\ $\dot{\mathrm{V}} \mathrm{CO}_{2}, \mathrm{CO}_{2}$ production \\ $\mathrm{Ra}$, rate of appearance
}

The process of birth constitutes the transition of the fetus, receiving its nutrient supply from the mother, to the newborn, deriving its energy and nutrient supply from intermittent feeding and endogenous sources. During the immediate postnatal period, there is a rapid decrease in plasma glucose concentration along with an increase in FFA and glycerol (1-3). The latter, representing an initiation of lipolysis in the adipose tissue, is associated with a shift in fuel source for energy from predominantly carbohydrates in utero to a carbohydrate and fat fuel mix in the extrauterine life $(4,5)$. Such a shift is also evidenced by the change in RQ, which declines to approximately 0.8 by $2 \mathrm{~h}$ of age, suggesting a significant contribution of fat to the oxidative metabolism (5-7). Within the adipose tissue, during lipolysis, triglycerides are hydrolyzed, resulting in release of FFA and glycerol. Although FFA may be reesterified locally in the adipose tissue, glycerol once released cannot be reused locally to synthesize triglycerides because of the absence of glycerokinase in the adipocytes (8). Finally, data in adult humans show that lipolysis in the adipose tissue is the major source of glycerol in blood (9). Thus, measurement of the $\mathrm{Ra}$ of glycerol in the circulation has been used to quantify the rate of lipolysis.

Diabetes in pregnancy exposes the fetus to a surfeit of metabolic nutrients and has been suggested to result in fetal and neonatal macrosomia (10). In spite of rigid control of maternal metabolism during pregnancy, fetal macrosomia and alterations in the concentration of circulating substrates persist in the neonate (10). Specifically, IDM have been shown to have lower concentrations of FFA in the immediate neonatal period, even though the plasma glucose and glycerol concentrations are similar to those in normal infants $(3,11)$. It has been hypothesized that the discrepancy between the plasma concentration of FFA and glycerol in the IDM may be related to increased reesterification of fatty acids in the adipocytes (3). In contrast, the SGA infant, as a result of intrauterine malnutrition, is born with decreased hepatic glycogen and adipose tissue triglyceride stores $(12-14)$. These infants have lower respiratory RQ compared with the normal infants (5). In neither the IDM nor SGA infants have the quantitative contribution of fat to oxidative metabolism or the quantitative measurement of lipolysis been done.

Limited information is available regarding the quantitative role of glycerol as glucogenic precursor in the newborn infant (15). Such a role for glycerol may be particularly important in the presence of hypoglycemia, such as in IDM and SGA infants. 
Using stable tracer-labeled glycerol and glucose in combination with respiratory calorimetry, the present study quantified the rates of glycerol turnover and its contribution to glucose and to expired $\mathrm{CO}_{2}$ in the newborn infants of normal and diabetic mothers as well as in SGA infants. In addition, from the measurements of lipolysis and fat oxidation, estimates of triglyceride fatty acid cycling were obtained in these three groups.

\section{MATERIALS AND METHODS}

Subjects. Healthy newborns less than $48 \mathrm{~h}$ old were recruited from the normal newborn nursery. Twelve AGA infants, eight SGA infants, and five IDM were studied. Birth weight percentiles were derived from the Colorado intrauterine growth chart, and SGA was defined as birth weight less than the 10th percentile for gestational age. Clinical characteristics of the newborns are shown in Table 1. As expected at similar gestational age, SGA newborns weighed significantly less $(p<0.001)$ and IDM were significantly heavier $(p<0.005)$ as compared with the AGA newborns. During the first $24 \mathrm{~h}$ after birth, the SGA newborns and IDM had their blood glucose monitored by chemical strips (Dextrostix; Ames Laboratories, Elkhart, IN) every hour for the first $4 \mathrm{~h}$ and thereafter before every 3-h feeding. Two AGA infants and one IDM were studied before their first feed; two AGA infants were fed maternal breast milk, and all the remaining infants were fed a commercial formula (Enfamil). None of the newborns studied developed symptoms of hypoglycemia, received glucose or parenteral fluid, or were on any medication, including antibiotics.

The metabolism of women with diabetes was regulated by multiple injections of insulin and by diet throughout pregnancy. Four mothers were treated with insulin; one had gestational diabetes and was managed by dietary regulation. Their average $\mathrm{HbA}_{1 \mathrm{c}}$ concentration was $7.6 \pm 1.6 \%$ (mean $\pm \mathrm{SD}$ ) during the 3rd trimester (normal for our laboratory is $<6.5 \%$ ).

The SGA infants were morphologically normal, had no evidence of intrauterine infection, and were born to healthy, normal women who had received no medication.

The study protocol was approved by the Institutional Committee on Investigation in Humans. After explanation of the study procedures, informed consent was obtained from the parents. The investigators were not responsible for the clinical care of the mother or the infant.

Study protocol. The studies were performed in the newborn metabolism study room in the Perinatal Clinical Research Center, where the ambient temperature was controlled at $28^{\circ} \mathrm{C}$ and humidity at $40 \%$. The newborns had received their last feeding at least $3 \mathrm{~h}$ (range $2.75-7 \mathrm{~h}$ ) before the start of tracer infusion, which lasted $5 \mathrm{~h}$ (Table 1). The infants were placed under the radiant warmer and thermoneutral environment was maintained throughout the study period. Two i.v. access lines were secured in the veins of opposite extremities using no. 23 scalp vein needles, for tracer infusion and for blood sampling. $\left[2-{ }^{13} \mathrm{C}\right]$ glycerol (71 atom \% ${ }^{13} \mathrm{C}$; Merck Sharpe \& Dohme Canada
Limited, Montreal, Canada) tracer solution was infused at a rate of $0.33 \pm 0.03 \mu \mathrm{mol} / \mathrm{kg} \cdot \min$ using an occlusive pump (model 903; Extracorporeal Medical Specialities, Inc., King of Prussia, PA). Six AGA and six SGA newborns and two IDM also received a simultaneous infusion of $\left[6,6-{ }^{2} \mathrm{H}_{2}\right]$ glucose $\left(98\right.$ atom $\%{ }^{2} \mathrm{H}$; Merck, Sharpe \& Dohme) tracer at a constant rate. No priming dose of the glycerol or glucose tracer was injected. Both tracers were infused for a period of $5 \mathrm{~h}$. Plasma glucose concentration was monitored throughout the study to ensure that no infant became hypoglycemic.

The sampling site was kept patent by infusing normal saline at $5 \mathrm{~mL} / \mathrm{h}$. Heparin was not used for this purpose. Blood samples were obtained in heparinized syringes at 30 -min intervals throughout the study, the sampling was less frequent in the SGA newborns. The total amount of blood drawn, in each infant, did not exceed $5 \%$ of the estimated blood volume $(85 \mathrm{~mL} / \mathrm{kg})$. Blood samples, on ice, were taken immediately to the laboratory, where $100 \mu \mathrm{L}$ of whole blood were used for evolution of $\mathrm{CO}_{2}$ in vacuum; plasma from the rest of the sample was stored at $-20^{\circ} \mathrm{C}$. Indirect respiratory calorimetry was done at 30 -min intervals (16). An open circuit flow-through system was used. A plastic hood was placed over the baby's head and a suction pump was used to draw air through the hood. The air exiting the hood was passed through a mixing chamber and the concentration of $\mathrm{O}_{2}$ and $\mathrm{CO}_{2}$ was measured using a medical gas analyzer (MGA-1 100; PerkinElmer, Pamona, CA). The flow of air through the system was measured and maintained by a servo-control flow regulator (Brooks Instrument, Hatfield, PA). The accuracy and reproducibility of the system was validated by combustion of absolute ethyl alcohol in the system, which gave results within $3-5 \%$ of expected values. At the end of the study, infusate solution was checked for sterility and an aliquot saved for later analysis. Actual tracer infusion rate was determined by time-calibrating the infusion pump using the same infusion tubings and needles. The isotopic enrichment and purity of the tracer was confirmed by GC-MS analysis.

Sample analysis. $\mathrm{CO}_{2}$ was evolved from the whole blood in vacuum by treating with perchloric acid and was collected by cryodistillation; its ${ }^{13} \mathrm{C}:{ }^{12} \mathrm{C}$ ratio was measured on a magnetic deflection double collector isotope ratio mass spectrometer $\mathrm{Nu}-$ clide Corp., State College, PA) (16). We have previously validated that the ${ }^{13} \mathrm{C}$ enrichment in blood bicarbonate during $\left[{ }^{13} \mathrm{C}\right]$ glucose infusion studies is similar to ${ }^{13} \mathrm{C}$ enrichment of breath $\mathrm{CO}_{2}(16)$.

Mass-spectrometric analysis of glycerol and glucose. Two hundred $\mu \mathrm{L}$ of plasma were deproteinized with equal volumes of $0.32 \mathrm{M}$ barium hydroxide and $0.32 \mathrm{M}$ zinc sulphate. Prepatory purification was done by ion exchange chromatography (17). Acetate derivatives of glycerol and glucose were prepared by adding $10 \mu \mathrm{L}$ of pyridine and $20 \mu \mathrm{L}$ of acetic anhydride to the dried eluted samples. The reaction mixture was incubated at room temperature for $1 \mathrm{~h}$. Derivatized samples were analyzed on the Hewlett-Packard GC-MS system (model 5985A; HewlettPackard Co., Palo Alto, CA). Samples were injected into a glass column (length $1.8 \mathrm{~m}$, inner diameter $3.2 \mathrm{~mm}$; Supelco, Inc.,

Table 1. Clinical characteristics of study subjects

\begin{tabular}{|c|c|c|c|c|c|}
\hline & Weight $(\mathrm{kg})$ & $\begin{array}{c}\text { Gestational } \\
\text { age } \\
\text { (wk) }\end{array}$ & $\begin{array}{c}\text { Apgar scores } \\
\text { (5 min })\end{array}$ & $\begin{array}{l}\text { Age at study } \\
\text { (h) }\end{array}$ & $\begin{array}{c}\text { Duration } \\
\text { of fast } \\
\text { (h)* }\end{array}$ \\
\hline $\operatorname{AGA}(n=12)$ & $3.16 \pm 0.37 \dagger$ & $39.7 \pm 1.2$ & $8-9$ & $\begin{array}{r}20.8 \pm 15.9 \\
(2.8-45.5)\end{array}$ & $5.0 \pm 1.3$ \\
\hline $\operatorname{IDM}(n=5)$ & $3.88 \pm 0.63 \ddagger$ & $39.2 \pm 1.1$ & 9 & $\begin{array}{r}19.4 \pm 15.2 \\
(2.0-43.0)\end{array}$ & $4.4 \pm 1.6$ \\
\hline SGA $(n=8)$ & $2.12 \pm 0.37 \S$ & $38.5 \pm 1.5$ & $8-9$ & $\begin{array}{r}26.7 \pm 14.6 \\
(9.5-45.5)\end{array}$ & $4.2 \pm 1.3$ \\
\hline
\end{tabular}

\footnotetext{
* Duration of fast before the start of tracer infusion, which lasted $5 \mathrm{~h}$.

$\uparrow$ Mean \pm SD.

$\ddagger p<0.005$ when compared with AGA.

$\S p<0.001$ when compared with AGA.
} 
Bellefonte, PA) packed with 3\% OV-17 mesh 100/120 (Alltech Associates, Inc., Applied Science Labs, Deerfield, IL). Helium was used as a carrier gas at a flow rate of $25 \mathrm{~mL} / \mathrm{min}$. The injection temperature was $220^{\circ} \mathrm{C}$, column temperature was $200^{\circ} \mathrm{C}$, and the GC-MS interphase temperature was $250^{\circ} \mathrm{C}$. Glycerol triacetate had a retention time of 3-4 min. Selected ion monitoring software was used to monitor $\mathrm{m} / \mathrm{z} 145(\mathrm{~m})$ and $\mathrm{m} / \mathrm{z}$ $146(\mathrm{~m}+1)$, representing unlabeled and ${ }^{13} \mathrm{C}$-labeled glycerol, respectively. After the elution of glycerol, the column temperature was increased to $240^{\circ} \mathrm{C}$ to elute glucose pentacetate, which had a retention time of $8-9 \mathrm{~min} . \mathrm{M} / \mathrm{z} 115$ and $\mathrm{m} / \mathrm{z} 116$, representing carbon 2,3 , and 4 of unlabeled and labeled glucose, respectively, were monitored. Monitoring of larger ions of glucose, e.g. $\mathrm{m} / \mathrm{z} 200$ and $\mathrm{m} / \mathrm{z} 201$, showed that glucose had a significant contribution from recycled mono-deuterated glucose in the $\left[6,6-{ }^{2} \mathrm{H}_{2}\right]$ glucose infusion studies (18). Deuterium enrichment of glucose in the plasma was determined as described previously (17).

Plasma and infusate glycerol concentrations and plasma betahydroxybutyrate were measured by fluorometric modification of enzymatic micromethods $(16,19)$. Glucose was measured by coupled hexokinase and glucose-6-phosphate dehydrogenase method on a centrifugal analyzer (Baker Instruments, Allentown, PA), and FFA was measured by calorimetric micromethod. Cpeptide and total and free insulin concentrations were measured by RIA (20). The lowest detectable levels by these methods were C-peptide $0.15 \mu \mathrm{g} / \mathrm{L}$, total insulin $6 \mathrm{mU} / \mathrm{L}$, and free insulin 4 $\mathrm{mU} / \mathrm{L}$.

Calculations. Glycerol and glucose turnover rates were calculated using the equation $\mathrm{Ra}=[(100 / \mathrm{Ep})-1] \times \mathrm{I}$, as described previously (21), where $\mathrm{Ra}=$ rate of appearance of substrate in the plasma $(\mu \mathrm{mol} / \mathrm{kg} \cdot \mathrm{min}), \mathrm{Ep}=$ steady state isotopic enrichment of the substrate in the plasma, and $\mathrm{I}=$ infusion rate of the isotopic tracer $(\mu \mathrm{mol} / \mathrm{kg} \cdot \mathrm{min})$.

$\dot{\mathrm{V}} \mathrm{O}_{2}(\mathrm{~mL} / \mathrm{kg} \cdot \mathrm{min})$ and $\dot{\mathrm{V}} \mathrm{CO}_{2}(\mathrm{~mL} / \mathrm{kg} \cdot \mathrm{min})$ were corrected by Haldane transformation and expressed at standard temperature and pressure. RQ was calculated as the ratio of $\dot{\mathrm{VCO}}_{2}$ to $\dot{\mathrm{V}}_{2}$. Nonprotein RQ was calculated based upon an $8 \%$ contribution of protein to total caloric expenditure in fasted newborns (22). The precursor production relationships were calculated as follows: Fraction of glycerol to glucose (Fglycerol $\rightarrow$ glucose) $=$ (Glucose $\mathrm{Ra} \times{ }^{13} \mathrm{C}$ enrichment glucose $\times 2$ ) / (Iglycerol $\times 0.71$ ), where Glucose $\mathrm{Ra}$ is the rate of appearance of glucose and the ${ }^{13} \mathrm{C}$ enrichment of plasma glucose represents carbons 2,3 , and 4 of glucose. The product of Glucose $\mathrm{Ra}$ and ${ }^{13} \mathrm{C}$ enrichment glucose was multiplied by 2 , assuming a symmetrical distribution of C-2 of glycerol on carbon 2 and 5 of glucose. Iglycerol was the infusion rate of tracer glycerol, and 0.71 was the ${ }^{13} \mathrm{C}$ enrichment of infused glycerol tracer.

Fraction of glucose from glycerol $=($ Glucose $\mathrm{Ra} \times 2) /($ Glycerol $\mathrm{Ra} \times$ fraction of glycerol to glucose).

Fraction of glycerol to $\mathrm{CO}_{2}$ (Fglycerol $\left.\rightarrow \mathrm{CO}_{2}\right)=\left(\dot{\mathrm{V}}_{\mathrm{CO}_{2}} \times{ }^{13} \mathrm{C}\right.$ enrichment of $\left.\mathrm{CO}_{2}\right) /($ Iglycerol $\times 0.71)$.

Fraction of $\mathrm{CO}_{2}$ from glycerol $\left(\mathrm{FCO}_{2} \leftarrow\right.$ glycerol $)=\dot{\mathrm{V} C \mathrm{O}_{2} /}$ (Glycerol $\mathrm{Ra} \times$ Fraction of glycerol to $\mathrm{CO}_{2} \times 3$ ).

The triglyceride-fatty acid cycling was quantified as described by Elia et al. (23). The amount of energy mobilized from adipose tissue was calculated from the release of glycerol (Ra), assuming that $1 \mathrm{~mol}$ of glycerol is released from $1 \mathrm{~mol}$ of triglyceride (dioleyl-palmityl-triglyceride $=8094 \mathrm{kcal} / \mathrm{mol}$ ). Quantitative estimates of fat oxidation were obtained from respiratory calorimetry measurements. The difference between energy mobilized and fat oxidized represents the amount of triglycerides recycled back to fat stores $(23,24)$.

Statistical analysis. IDM and SGA groups were compared with the AGA group using two-tailed $t$ test. Data within the group were compared using paired $t$ test. Differences were considered significant at $p<0.05$.

\section{RESULTS}

Substrate concentrations (Table 2). At the start of the study, the plasma glucose concentration was significantly lower in the IDM $(p<0.05)$ and the SGA infants $(p<0.005)$ as compared with the AGA infants. As a result of continued fasting, there was a small decrease in glucose concentration in the AGA infants by the end of the tracer infusion period (Fig. 1). No decrease in glucose concentration was observed in IDM or SGA infants. However, after $8 \mathrm{~h}$ of fasting, plasma glucose was still significantly lower in SGA as compared with AGA infants $(p<0.01)$.

There was no difference in the plasma glycerol (Fig. 2) and FFA concentrations in the three groups, neither at the beginning nor at the end of the study. The concentration of both glycerol and FFA was higher at time 0 than at $60 \mathrm{~min}$, probably representing the stress of needle puncture and other manipulations. The betahydroxybutyrate concentration was lower, although not statistically significant, in the IDM and SGA infants $(p=0.06)$ as compared with AGA infants. There was a continuous increase in betahydroxybutyrate concentration throughout the study so that by $300 \mathrm{~min}$ betahydroxybutyrate concentrations had significantly increased from the basal levels in both AGA $(p<0.001)$ and SGA $(p<0.01)$ infants.

The mean plasma C-peptide concentration in IDM infants $(0.71 \pm 0.14 \mu \mathrm{g} / \mathrm{L})$ was significantly greater compared with that in AGA infants $(0.30 \pm 0.14 \mu \mathrm{g} / \mathrm{L}, p<0.01)$. Although total insulin was higher in IDM as compared with AGA infants, the free insulin levels were similar in the two groups (AGA $4.4 \pm$ $0.79 \mathrm{mU} / \mathrm{L}, \mathrm{IDM} 5.3 \pm 0.05 \mathrm{mU} / \mathrm{L}$ ). Plasma was insufficient to measure insulin in SGA infants.

Respiratory calorimetry. $\dot{\mathrm{V}}_{2}, \dot{\mathrm{V}}_{\mathrm{CO}_{2}}$, and $\mathrm{RQ}$ were measured in a quiet state. Two to four recordings of 15-20 min each over 1-2 $\mathrm{h}$ were averaged in each newborn. As shown in Figure 3, the $\dot{\mathrm{V}} \mathrm{O}_{2}$ and $\dot{\mathrm{V}}_{\mathrm{CO}_{2}}$ were similar in the three groups. RQ was also not significantly different in the IDM and SGA infants when compared with AGA infants.

Glycerol kinetics in newborn. The ${ }^{13} \mathrm{C}$ enrichment of plasma glycerol, glucose [m/z 116/115, representing C2, 3, and 4], and expired $\mathrm{CO}_{2}$ for the AGA infants are displayed in Figure 4. As shown, a steady state was achieved during the last $3 \mathrm{~h}$ of the study for glycerol and during the last $2 \mathrm{~h}$ for glucose. The ${ }^{13} \mathrm{C}$ enrichment of the plasma bicarbonate approached plateau by $4 \frac{1}{2}-5$ h. Because plateau enrichment of $\mathrm{CO}_{2}$ was not observed in all instances, it may have resulted in underestimation, probably small, of the contribution of glycerol carbon to $\mathrm{CO}_{2}$.

The Ra of glycerol, calculated by tracer dilution during steady state, was similar in the AGA infants and IDM-approximately $9.5 \mu \mathrm{mol} / \mathrm{kg} \cdot \min ($ Table 3). Glycerol Ra was significantly higher $(p<0.05)$ in the SGA infants. Glucose Ra was quantified in the six SGA and six AGA infants. The glucose Ra was more variable in SGA infants; however, mean glucose turnover rate was not significantly different as compared with that in AGA infants. The rate of glucose turnover in two IDM was 28 and $26 \mu \mathrm{mol} /$ $\mathrm{kg}$. min. No correlation between glycerol flux and plasma glycerol concentration was observed in any group or in the entire infant population.

Fate of glycerol carbon in human newborn. The contribution of glycerol to glucose and to expired $\mathrm{CO}_{2}$ was calculated by examining the precursor-product relation. As shown (Table 3), the major component (over $81 \%$ ) of glycerol flux was converted to glucose. The glucogenic contribution of glycerol (Fglucose from glycerol) was determined to be $20 \%$ in AGA infants, SGA infants, and the two IDM.

During the last $30 \mathrm{~min}$ of the study, approximately $35 \%$ of the glycerol carbon was recovered in the blood bicarbonate pool, and $5 \%$ of the $\mathrm{CO}_{2}$ produced could be accounted for by glycerol oxidation (Table 4). The fraction of $\mathrm{CO}_{2}$ derived from glycerol and the fraction of glycerol to $\mathrm{CO}_{2}$ was similar in the three groups.

There was a significant positive correlation between glycerol 
GLYCEROL METABOLISM IN THE NEWBORN INFANT

Table 2. Plasma concentration of circulating substrates during study*

\begin{tabular}{|c|c|c|c|c|c|c|c|c|}
\hline & \multicolumn{2}{|c|}{ Glucose $(\mathrm{mM} / \mathrm{L})$} & \multicolumn{2}{|c|}{ Glycerol $(\mu \mathrm{mol} / \mathrm{L})$} & \multicolumn{2}{|c|}{$\mathrm{FFA}(\mathrm{mmol} / \mathrm{L})$} & \multicolumn{2}{|c|}{$\mathrm{B}(\mathrm{OH})$ butyrate $(\mathrm{mmol} / \mathrm{L})$} \\
\hline & $0 \mathrm{~h}$ & $5 \mathrm{~h}$ & $\mathrm{Oh}$ & $5 \mathrm{~h}$ & $0 \mathrm{~h}$ & $5 \mathrm{~h}$ & $0 \mathrm{~h}$ & $5 \mathrm{~h}$ \\
\hline AGA & $3.23 \pm 0.80$ & $2.99 \pm 0.24$ & $231 \pm 72$ & $159 \pm 40$ & $1.07 \pm 0.58$ & $0.84 \pm 0.48$ & $0.40 \pm 0.33$ & $0.59 \pm 0.39 \dagger$ \\
\hline IDM & $2.41 \pm 0.93 \ddagger$ & $2.74 \pm 0.54$ & $248 \pm 67$ & $160 \pm 39$ & $1.11 \pm 0.42$ & $0.79 \pm 0.23$ & $0.22 \pm 0.10$ & $0.33 \pm 0.21$ \\
\hline SGA & $2.13 \pm 0.67 \S$ & $2.39 \pm 0.51 \|$ & $178 \pm 77$ & $138 \pm 56$ & $1.20 \pm 0.83$ & $0.96 \pm 0.49$ & $0.19 \pm 0.12$ & $0.35 \pm 0.099$ \\
\hline
\end{tabular}

* The data at $5 \mathrm{~h}$ are the mean of observation during the 4 th and 5 th $\mathrm{h}$ of tracer infusion.

$\dagger$ Paired $t$ test with time $0, p<0.01$.

$\ddagger p<0.05$ compared with AGA infants.

$\S p<0.005$ compared with AGA infants.

$\| p<0.01$ compared with AGA infants.

I Paired $t$ test with time $0, p<0.01$.

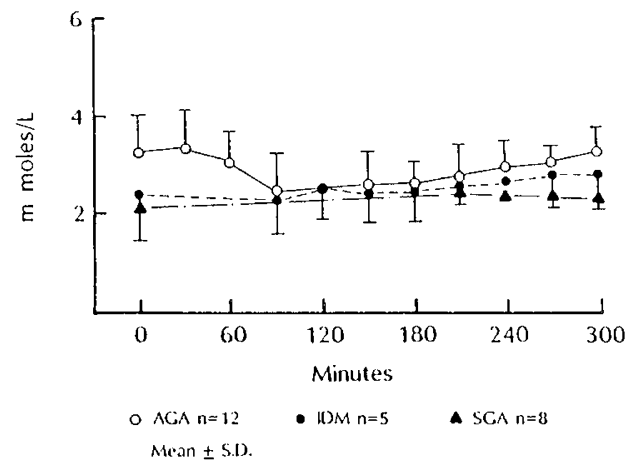

Fig. 1. Plasma glucose concentration in the newborn infants during the study (mean $\pm \mathrm{SD}$ ). The infants were fasted for at least $3 \mathrm{~h}$ before the study $(0 \mathrm{~min})$ and remained fasted throughout the $300 \mathrm{~min}$ of the study period.

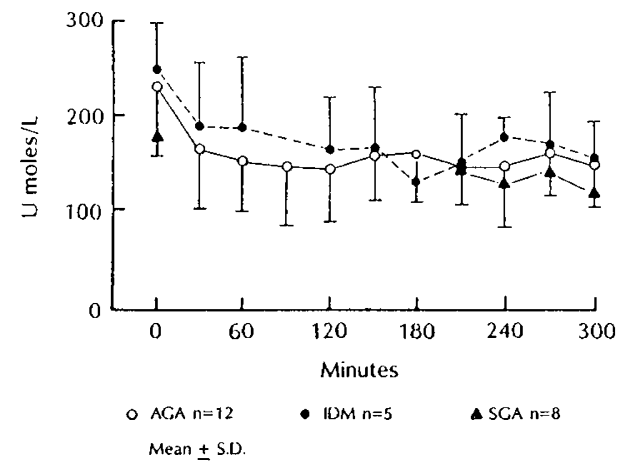

Fig. 2. Plasma glycerol concentration in newborn infants during the study (mean $\pm \mathrm{SD}$ ). The infants were fasted for at least $3 \mathrm{~h}$ before the study $(0 \mathrm{~min})$ and remained fasted throughout the $300 \mathrm{~min}$ of the study period.

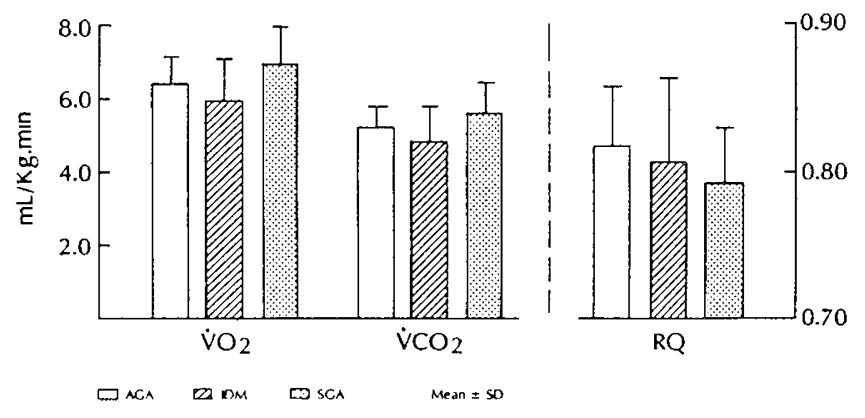

Fig. 3. Rate of $\dot{\mathrm{VO}}_{2}$, rate of $\dot{\mathrm{V}}_{2}$, and RQ.

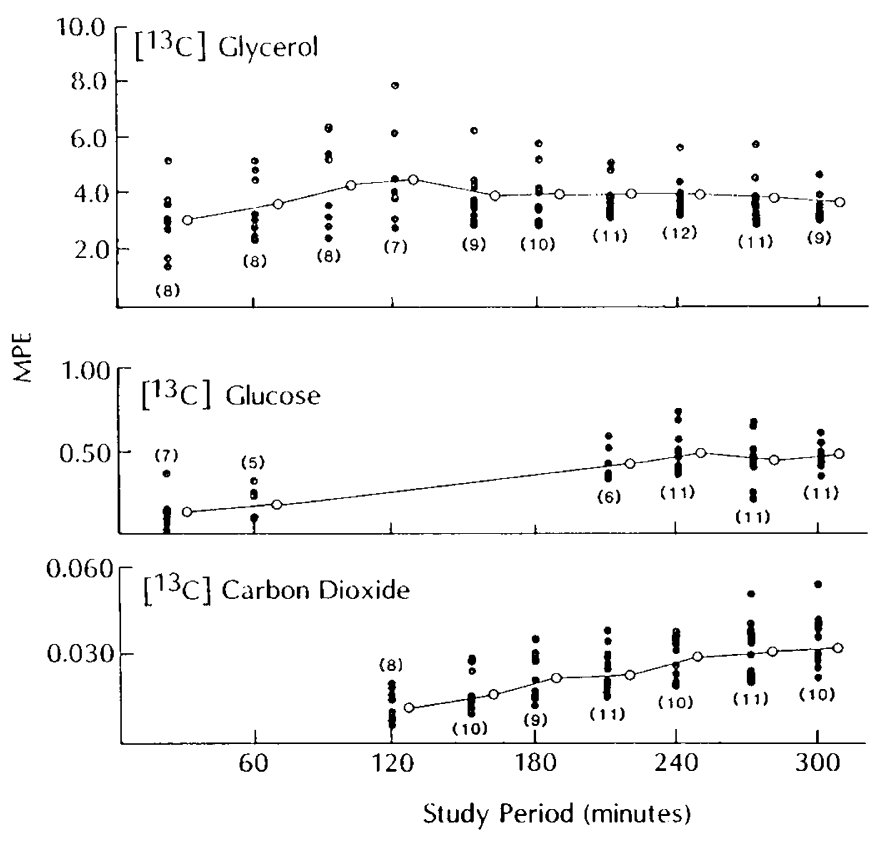

Fig. 4. Changes in ${ }^{13} \mathrm{C}$ enrichment of glycerol, glucose, and $\mathrm{CO}_{2}$ (bicarbonate) throughout the study. $\left[2-{ }^{13} \mathrm{C}\right]$ glycerol was infused at a constant rate in 12 AGA newborns. MPE, moles \% excess (the natural background enrichment has been substracted from the data reported).

flux and the fraction of $\mathrm{CO}_{2}$ from glycerol in $\mathrm{AGA}$ infants and IDM (Figs. 5 and 6).

$$
\begin{gathered}
\text { AGA } y=-0.821+0.53 x ; p=0.001 ; r=0.84 \\
\text { IDM } y=0.127+0.49 x ; p=0.02 ; r=0.93
\end{gathered}
$$

Triglyceride-fatty acid cycle. The triglyceride energy mobilized was calculated from the rate of glycerol release. As shown in Table 5, the energy released from the hydrolysis of triglyceride was increased in the SGA infants. However, only 22 to $24 \%$ of energy released was oxidized to $\mathrm{CO}_{2}$, with the majority (76-78\%) being recycled back to the adipose tissue. This estimation represents the total triglyceride-fatty acid cycle and does not distinguish between extra- and intracellular compartments. The energy cost $(\mathrm{kcal} / \mathrm{kg} \cdot \mathrm{d})$ of triglyceride recycling was $1.52 \pm 0.46$ in AGA infants, $1.54 \pm 0.42$ in IDM, and $2.08 \pm 0.86$ in SGA infants, representing $3.5,3.9$, and $4.4 \%$ of the resting energy consumption, respectively.

\section{DISCUSSION}

In the present study, using isotopic tracer methods and respiratory calorimetry, we have observed that 1 ) lipolysis, as measured by glycerol release, is active in the newborn infant; 2) glycerol is a significant glucogenic precursor in the newborn 
Table 3. Glycerol-glucose metabolism in newborn*

\begin{tabular}{|c|c|c|c|c|c|c|}
\hline & $\begin{array}{c}\text { Glycerol turnover } \\
(\mu \mathrm{mol} / \mathrm{kg} \cdot \mathrm{min})\end{array}$ & $\begin{array}{l}\text { Glucose turnover } \\
(\mu \mathrm{mol} / \mathrm{kg} \cdot \mathrm{min})\end{array}$ & F Glycerol $\rightarrow$ glucose & $\begin{array}{l}\text { Q Glycerol } \rightarrow \text { glucose } \\
(\mu \mathrm{mol} / \mathrm{kg} \cdot \mathrm{min})\end{array}$ & F Glucose «glycerol & $\begin{array}{l}\text { Q Glucose } \leftarrow \text { glycerol } \\
(\mu \mathrm{mol} / \mathrm{kg} \cdot \mathrm{min})\end{array}$ \\
\hline $\mathrm{AGA}$ & $\begin{array}{c}9.47 \pm 2.11 \\
(n=12)\end{array}$ & $\begin{array}{c}21.09 \pm 1.71 \\
(n=6)\end{array}$ & $\begin{array}{c}0.87 \pm 0.16 \\
(n=6)\end{array}$ & $\begin{array}{c}8.69 \pm 2.60 \\
(n=6)\end{array}$ & $\begin{array}{c}0.20 \pm 0.06 \\
(n=6)\end{array}$ & $\begin{array}{c}4.34 \pm 1.30 \\
(n=6)\end{array}$ \\
\hline IDM & $\begin{array}{l}9.55 \pm 2.14 \\
(n=5)\end{array}$ & $28.3,26.6$ & $0.9,1.2$ & $11.41,9.92$ & $0.20,0.19$ & $5.71,4.96$ \\
\hline SGA & $\begin{array}{c}12.15 \pm 3.87 \dagger \\
(n=8)\end{array}$ & $\begin{array}{c}23.08 \pm 4.74 \\
(n=6)\end{array}$ & $\begin{array}{c}0.82 \pm 0.25 \\
(n=6)\end{array}$ & $\begin{array}{c}9.05 \pm 2.92 \\
(n=6)\end{array}$ & $\begin{array}{c}0.20 \pm 0.06 \\
(n=6)\end{array}$ & $\begin{array}{c}4.52 \pm 1.46 \\
(n=6)\end{array}$ \\
\hline
\end{tabular}

${ }^{*} \mathrm{~F}$, fraction of; $\mathrm{Q}$, quantity of.

$\dagger p<0.05(0.03)$ as compared with AGA infants.

Table 4. Oxidative fate of glycerol carbon in human newborn*

\begin{tabular}{|c|c|c|c|c|}
\hline & $\begin{array}{c}\text { Glycerol Ra } \\
(\mu \mathrm{mol} / \mathrm{kg} \\
\cdot \mathrm{min})\end{array}$ & $\begin{array}{c}\dot{\mathrm{VCO}_{2}} \\
(\mu \mathrm{mol} / \mathrm{kg} \\
\cdot \mathrm{min}) \\
\end{array}$ & $\begin{array}{c}\text { F Glycerol } \rightarrow \\
\mathrm{CO}_{2}\end{array}$ & $\mathrm{~F} \mathrm{CO}_{2} \leftarrow$ glycerol \\
\hline AGA & $\begin{array}{c}9.47 \pm 2.11 \\
(n=12)\end{array}$ & $\begin{array}{l}229 \pm 29 \\
(n=12)\end{array}$ & $\begin{array}{c}0.33 \pm 0.05 \\
(n=11)\end{array}$ & $\begin{array}{c}0.044 \pm 0.013 \\
(n=11)\end{array}$ \\
\hline IDM & $\begin{array}{c}9.55 \pm 2.14 \\
(n=5)\end{array}$ & $\begin{array}{l}211 \pm 40 \\
(n=5)\end{array}$ & $\begin{array}{c}0.36 \pm 0.08 \\
(n=5)\end{array}$ & $\begin{array}{c}0.049 \pm 0.011 \\
(n=5)\end{array}$ \\
\hline SGA & $\begin{array}{c}12.15 \pm 3.87 \dagger \\
(n=8)\end{array}$ & $\begin{array}{l}246 \pm 42 \\
(n=6)\end{array}$ & $\begin{array}{c}0.36 \pm 0.08 \\
(n=6)\end{array}$ & $\begin{array}{c}0.046 \pm 0.012 \\
(n=6)\end{array}$ \\
\hline
\end{tabular}

$* \mathrm{~F}$, fraction of.

$\uparrow p<0.03$ compared with AGA infants.

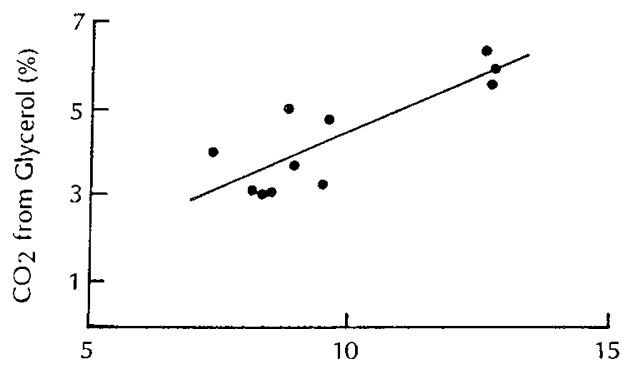

Glycerol Flux ( $\mu \mathrm{mole} / \mathrm{Kg} \cdot \mathrm{min})$

Fig. 5. Relation between fraction of $\mathrm{CO}_{2}$ from glycerol and glycerol flux in AGA infants. $y=-0.82+0.53 x ; r=0.84 ; p=0.001$.

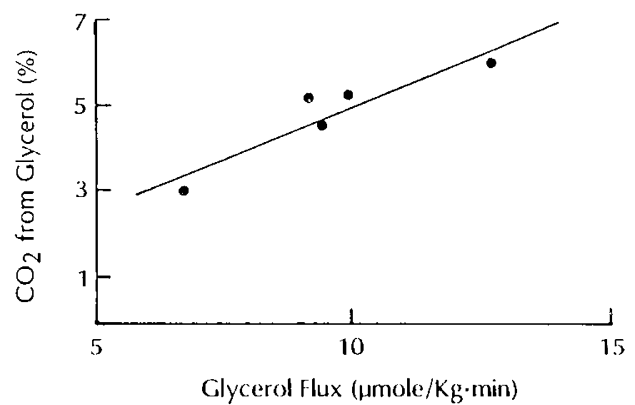

Fig. 6. Relation between fraction of $\mathrm{CO}_{2}$ from glycerol and glycerol flux in IDM. $y=0.127+0.49 x ; r=0.93 ; p=0.02$.

Table 5. Triglyceride-fatty cycle in newborn infants

\begin{tabular}{lccc}
\hline & $\begin{array}{c}\text { Triglyceride } \\
\text { energy mobilized } \\
\left(\mathrm{kcal} \cdot \mathrm{kg}^{-1} \cdot \mathrm{d}^{-1}\right)\end{array}$ & $\begin{array}{c}\text { Fatty acid oxidized } \\
\left(\mathrm{kcal} \cdot \mathrm{kg}^{-1} \cdot \mathrm{d}^{-1}\right)\end{array}$ & Recycled \\
\hline Normal & $110.4 \pm 24.6$ & $24.8 \pm 6.4$ & $0.76 \pm 0.07$ \\
IDM & $111.3 \pm 24.9$ & $24.9 \pm 10.4$ & $0.77 \pm 0.10$ \\
SGA & $141.6 \pm 45.1$ & $30.4 \pm 6.3$ & $0.78 \pm 0.08$ \\
\hline
\end{tabular}

infant, representing as much as $20 \%$ of glucose turnover; 3) $35 \%$ of glycerol carbon is converted to $\mathrm{CO}_{2}$, representing $5 \%$ of $\mathrm{CO}_{2}$ production, and glycerol oxidation to $\mathrm{CO}_{2}$ is via its conversion to glucose; 4) possibly as a result of improved management of maternal metabolism, glycerol metabolism in the IDM was noted to be normal; and 5) lipolysis was observed to be increased in SGA infants.

The following potential problems in the experimental methods and the expression of data, unique to the newborn population, need to be recognized: 1) We had chosen to infuse the tracer in the peripheral vein and obtain blood samples from the peripheral vein of the opposite extremity. Although venous-arterial infusion sampling mode, i.e. tracer infusion in a vein and sampling of arterial blood, may be the most appropriate method for quantifying glycerol kinetics (25-27), ethical considerations do not permit placement of arterial lines in healthy newborn infants. In any case, the error as a result of tracer dilution by the glycerol release from the hand in a blood sample obtained from the dorsum of the hand should be small when compared with the total glycerol turnover. Similarly, although some glycerol can be oxidized by the muscle, at least in the human adult (28), the contribution of the local muscle oxidation in relation to the total body glycerol oxidation is likely to be small, particularly in view of the observation that more than $80 \%$ of glycerol was converted to glucose. Therefore, the ${ }^{13} \mathrm{C}$ enrichment of bicarbonate in the venous blood should have minimal contribution from local glycerol oxidation. Thus, one can assume that the reported measurements of glycerol metabolism are close approximations of the actual kinetics. 2) All the data have been expressed in relation to total body weight. Although the data on energy consumption and maybe glycerol kinetics could be better expressed in relation to lean body mass, calculation of the data based upon lean body mass is not likely to make any difference in the results. Specifically, the small but not significant differences among the three groups in $\dot{\mathrm{V}}_{2}$ measurements (Fig. 3) will actually disappear when the data are expressed in relation to lean body mass, without having any effect on RQ measurement. The higher glycerol turnover rates in the SGA infants are consistent with the lower RQ observed in this group.

Glycerol turnover in newborn infants. The rate of turnover of glycerol in healthy, normal AGA infants was $9.5 \mu \mathrm{mol} / \mathrm{kg} \cdot \mathrm{min}$. Bougneres et al. (15), using a similar isotopic tracer method and under similar experimental conditions in five infants, estimated the turnover rate of glycerol to be $4.4 \mu \mathrm{mol} / \mathrm{kg} \cdot \mathrm{min}$. The reason for these differences remains unclear and may be related to other factors such as prior glucose infusion and subtle clinical differences in the study populations. In addition, the total duration of the fast, from the last meal to the time of isotopic steady state measurements, in our study was 7 to $9 \mathrm{~h}$, in contrast to the previous study, where it was maximally $6 \mathrm{~h}$. All infants in the present study were healthy, full-term, AGA infants and were not receiving glucose or antibiotics for any clinical indications.

In lean, healthy adults, after an overnight fast, the rate of glycerol turnover has been reported to be $1.5-2.5 \mu \mathrm{mol} / \mathrm{kg} \cdot \mathrm{min}$ $(23,29-31)$. With prolonged fasting, an increase in lipolysis and glycerol turnover has been reported so that between 3 and $15 \mathrm{~d}$ of fasting the rate of glycerol flux ranged between 3.3 and 5.8 $\mu \mathrm{mol} / \mathrm{kg} \cdot \mathrm{min}(30,31)$. The rates of glycerol flux in the newborn infant in the present study were much higher than those observed in adults, even after prolonged fasting. Lipolysis has been considered to reflect the energy requirement of the lean body mass 
(32). Even though the lean body mass of the newborn is less compared with that of the adult (40 versus $70 \%$ ), the greater energy requirements of the neonate will result in early depletion of glycogen stores and an early recruitment of fat for energy and thus a higher flux rate of glycerol and fatty acids in the infants. The higher flux rates of these substrates are also reflected in higher circulating levels of FFA and glycerol. The mediators of these responses in the newborn may be the lower insulin levels and the relatively higher catecholamine levels during the immediate postnatal period of extrauterine adaptation. In addition, as shown by Marcus et al. (33), thyrotropin may have a major lipolytic role in this age group.

Glycerol-glucose relationship. The major metabolic fate of glycerol in man and animals is conversion to glucose. The key enzyme involved in the regulation of the utilization of glycerol, glycerokinase, is present in significant quantities only in liver, kidney, and small intestine. The major site of glucogenesis from glycerol is liver and kidney $(8,34)$. Vernon and Walker $(35)$ have demonstrated a marked increase after birth in the ability of both the liver and kidney slices from the neonatal rat to convert glycerol into glucose plus glycogen. In addition, this increase was correlated with the increase in glycerol kinase activity. Similar observations of an increase in enzymes of glycerol metabolism in the liver after birth were reported by other investigators ( 36 , 37). Quantitatively, in the 0 - to 4-d-old newborn dogs, Hall et al. (38) reported that approximately $50 \%$ of glycerol carbon was converted to glucose, accounting for $14 \%$ of glucose carbon. This was in contrast to adult dogs, in which glycerol accounted for only $6 \%$ of glucose carbon released in circulation $(38,39)$. In lean and obese human adults after a short fast, 38 and $56 \%$, respectively, of glycerol turnover is converted to glucose, representing 3 and $8 \%$, respectively, of glucose released in blood (31). A prolonged fast resulted in a marked increase in both conversion of glycerol to glucose and in the contribution of glycerol to glucose turnover (31). In contrast, in the normal newborn infants in the present study, $87 \%$ of glycerol turnover was converted to glucose after $7-9$ h of fasting, representing $20 \%$ of glucose turnover. These data are of similar magnitude as those seen in human adults after a prolonged fast (31) and demonstrate the speed by which a neonate can mimic the fasting state in adults, possibly because of its high energy demands in relation to available glycogen stores. Our data are similar to those reported by Bougneres et al. (15), who showed that $73 \%$ of glycerol turnover was converted to glucose in five full-term infants. However, they reported that a maximum of $7 \%$ of glucose turnover could possibly come from glycerol. The difference between their study and the data reported by us primarily lies in the differences in glucose turnover rates measured in the two studies. Again, these differences may be related to the duration of fasting and the clinical study populations.

Two methodologic problems need to be considered in relation to glycerol-glucose relationship. First, we have assumed an equal distribution of the tracer ${ }^{13} \mathrm{C}$ in carbon 2 and 5 of glucose. Studies in the rat have demonstrated an asymmetrical distribution (40, 41 ). Although no such data are available, particularly in the human newborn infants, our calculation of the data, assuming symmetrical distribution, would result in a small overestimation $(\sim 17 \%)$ of glycerol's contribution to glucose. Second, some of the tracer ${ }^{13} \mathrm{C}$ incorporated into glucose could recycle back to glucose after the metabolism of glucose to pyruvate, resulting in a higher ${ }^{13} \mathrm{C}$ enrichment of glucose (18). However, the recycled tracer carbon $\left({ }^{13} \mathrm{C}\right)$ will be significantly diluted. Furthermore, randomization of carbon during resynthesis of glucose and the ion species measured, representing carbon 2,3 , and 4 of glucose, will further decrease the possibility of this overestimation (18).

Oxidation of glycerol in neonates. In the newborn infant, about $33 \%$ of glycerol appearing in the circulation was oxidized to $\mathrm{CO}_{2}$; however, it contributed less than $5 \%$ to overall $\dot{\mathrm{VCO}}_{2}$ and thus to energy metabolism. Almost all of the glycerol oxidized to $\mathrm{CO}_{2}$ was via its first conversion to glucose. As in any precursor- product relationship measured by tracer isotopes, the oxidation of glycerol could potentially be underestimated because of dilution of the tracer in the intermediate pools. Nevertheless, these data show that glycerol is a minor source of energy for the newborn. No other data regarding glycerol oxidation in the human newborn have been reported. The present estimate by tracer isotope methods is similar to those derived from the previously reported rates of glucose oxidation in the newborn $(\sim 50 \%)$ and the reported rate of conversion of glycerol to glucose $(\sim 70-80 \%)$ (16). Similar to the data in infants, in the human adult only $2-5 \%$ of $\mathrm{CO}_{2}$ was derived from glycerol after a short fast and only a small increase was seen when fasting was prolonged (39). It is significant to note that after a prolonged fast in these adult subjects there was a marked increase in glycerol turnover. These latter data are in contrast to those from infants, in whom the fraction of $\mathrm{CO}_{2}$ derived from glycerol was significantly correlated with the glycerol flux (Figs. 5 and 6). Again, these differences in the adult and the newborn are probably related to the differences in the rates of energy consumption in the two groups. Further, the increased oxidation of glycerol with increased glycerol flux may result in sparing of other metabolizable fuels, particularly proteins.

Glycerol metabolism in IDM. Our study did not demonstrate any significant effect of maternal diabetes upon neonatal glycerol and fat metabolism. Even though the C-peptide levels were significantly elevated in the IDM, their free insulin concentration was similar to that in normal infants. Furthermore, the plasma concentrations of glucose, FFA, and glycerol were comparable in the two groups. These data suggest that, possibly as a result of rigorous regulation of maternal metabolism during pregnancy, the glycerol and energy metabolism in the IDM was normalized. Our data do not present evidence for increased reesterification of FFA in the adipose tissue of IDM as hypothesized previously (3).

$S G A$ infants. As anticipated, the SGA infants, who are born with relatively lower glycogen stores, had higher rates of lipolysis and a slightly increased $(p=0.06)$ contribution of fat to energy metabolism. Their plasma glucose concentration was lower than that in AGA infants and remained low throughout the study. The parameters of glycerol metabolism were similar in the SGA and AGA infants. These infants, however, were not severely SGA; thus, marginal malnutrition appears to cause minor changes in fat and energy metabolism.

Triglyceride-fatty acid cycle in newborn infants. Quantitative estimates of the triglyceride-fatty acid substrate cycle have been made in vivo in adult man and animals as well as in vitro in isolated adipose tissue $(23,24,42-44)$. These data show that only a small fraction, $20-30 \%$, of the fatty acid released from the adipose tissue is oxidized and that the majority of the released fatty acids are recycled back to adipose tissue and resynthesized into triglycerides. The differences in estimates observed in various studies probably reflect the differences in experimental techniques used and the metabolic state of the individuals (23, 42, 43). Nevertheless, the data in adult humans and animals suggest that the triglyceride-fatty acid cycle is regulated by catecholamines and insulin and that it plays an important role in energy metabolism in humans (24). Specifically, it has been suggested that changes in substrate cycling contribute to the increased thermogenesis after severe burns in humans (45), to the increased metabolic rate of cachectic patients with esophageal cancer (46), and to the amplification of substrate flux and responsiveness during exercise (43). Finally, triglyceride-fatty acid cycle has been observed to be markedly increased in states of substrate privation such as short-term fasting in man (30). The present data are the first estimate of triglyceride-fatty acid cycling in newborn infants. Interestingly, these data show that although the magnitude of lipolysis expressed per unit body weight is markedly increased in newborn infants compared with adults, the fraction of fatty acids released that was recycled back to triglycerides was of similar magnitude $(\sim 75 \%)$ as was seen in 
adults. Furthermore, no effect of maternal diabetes on triglyceride-fatty acid cycling in the infant was observed. This may be the result of good management of maternal diabetes, because, unlike the previous observations, the free insulin levels in the IDM were similar to those in normal newborn infants. In addition, the increased fatty acid oxidation observed in SGA infants was associated with increased triglyceride mobilization as well as recycling. It is significant to note that the fraction of triglyceride energy recycled was similar in the three groups (76\%) and that energy cost of the recycling represented similar fractions of the resting energy consumption in the three groups. Thus, as suggested by Newsholme and Crabtree (47), these high rates of substrate cycling in the newborn infants may provide increased sensitivity or the ability to amplify metabolic control systems when required.

In summary, our data show that lipolysis is active in the immediate neonatal period in normal infants, SGA infants, and IDM. Lipolysis and the contribution of fat to oxidative metabolism was increased in SGA infants. The major metabolic fate of glycerol in the human newborn was shown to be conversion to glucose and to energy substrate via its conversion to glucose. Our data show that triglyceride-fatty acid cycling is markedly increased in the newborn compared with adults. Finally, maternal diabetes and intrauterine growth retardation did not have any effect on these parameters.

Acknowledgment. The authors thank Ellen Brown and Monica Bakaitis for technical help, Karen Rossi for help with data analysis, and Joyce Nolan for help with preparation of the manuscript.

\section{REFERENCES}

1. Persson B, Gentz J 1966 The pattern of blood lipids, glycerol and ketone bodies during the neonatal period, infancy and childhood. Acta Paediatr Scand 55:353-362

2. Melichar V, Wolf $H 1967$ Postnatal changes in the blood serum content of glycerol and free fatty acids in premature infants influence of hypothermia and of respiratory distress. Biol Neonate 11:50-60

3. Persson B, Gentz J, Kellum M 1973 Metabolic observations in infants of strictly controlled diabetic mothers. Plasma levels of glucose, FFA, glycerol and D-betahydroxybutyrate during the first two hours after birth. Acta Paediatr Scand 62:465-473

4. Morriss FH, Makowski EL, Meschia G, Battaglia FC 1975 The glucose/oxygen quotient of the term human fetus. Biol Neonate 25:44-52

5. Senterre J, Karlberg P 1970 Respiratory quotient and metabolic rate in normal full-term and small-for-date newborn infants. Acta Paediatr Scand 59:653658

6. Tunell R, Copher D, Persson B 1976 The pulmonary gas exchange and blood gas changes in connection with birth. In: Stetson JB, Swyer PR (eds) Neonatal Intensive Care. Warren H Green, St Louis, pp 89-109

7. Gentz J, Kellum M, Persson B 1976 The effect of feeding on oxygen consumption, RQ and plasma levels of glucose, FFA, and D-betahydroxybutyrate in newborn infants of diabetic mothers and small for gestational age infants. Acta Paediatr Scand 65:445--454

8. Lin ECC 1977 Glycerol utilization and its regulation in mammals. Annu Rev Biochem 46:765-795

9. Nurjhan N, Kennedy F, Consoli A, Martin C, Miles J, Gerich J 1988 Quantification of the glycolytic origin of plasma glycerol: implications for the use of the rate of appearance of plasma glycerol as an index of lipolysis in vivo. Metabolism 37:386-389

10. Berk MA, Mimouni F, Miodovnik M, Hertzberg V, Valuck J 1989 Macrosomia in infants of insulin-dependent diabetic mothers. Pediatrics 83:1029-1034

11. Persson B, Gentz J, Kellum M, Thorell J 1976 Metabolic observations in infants of strictly controlled diabetic mothers. II. Plasma insulin, FFA, glycerol, betahydroxybutyrate during intravenous glucose tolerance test. Acta Paediatr Scand 65:1-9

12. Ogata ES, Swanson SL, Collins Jr JW, Finley SL 1990 Intrauterine growth retardation: altered hepatic energy and redox states in the fetal rat. Pediatr Res 27:56-63

13. Haymond MW, Karl IE, Pagliara AS 1974 Increased gluconeogenic substrates in the small-for-gestational-age infant. N Engl J Med 291:322-328

14. de Leeuw R, de Vries IV 1976 Hypoglycemia in small-for-dates newborn infants. Pediatrics 58:18-22
15. Bougneres PF, Karl IE, Hillman LS, Bier DM 1982 Lipid transport in the human newborn. Palmitate and glycerol turnover and the contribution of glycerol to neonatal hepatic glucose output. J Clin Invest 70:262-270

16. Denne SC, Kalhan SC 1986 Glucose carbon recycling and oxidation in human newborns. Am J Physiol 251:E7 1-E77

17. Kalhan SC, Tserng K-Y, Gilfillan C, Dierker LJ 1982 Metabolism of urea and glucose in normal and diabetic pregnancy. Metabolism 31:824-833

18. Kalhan SC 1990 Stable isotope tracers for studies of glucose metabolism. J Lab Clin Med 116:615-622

19. Wieland O 1981 Glycerol UV-method. In: Bergmeyer HU (ed) Methods of Enzymatic Analysis, Vol 3. Verlag Chemie International, Deerfield Beach, FL, pp 1404-1409

20. Kuzuya H, Blix PM, Horwitz DL, Steiner DF, Rubenstein AH 1977 Determination of free and total insulin and C-peptide in insulin-treated diabetics. Diabetes 26;22-29

21. Tserng K-Y, Kalhan SC 1983 Calculation of substrate turnover rate in stable isotope tracer studies. Am J Physiol 245:E308-E311

22. Kalhan SC, Gilfillan CA 1985 Intrauterine nutrition and the newborn. Proceedings of the Oxford Symposium. In: Jones CT, Nathanielsz PW (eds), The Physiological Development of the Fetus and Newborn. Academic Press, Orlando, FL, pp 739-746

23. Elia M, Zed C, Neale G, Livesey G 1987 The energy cost of triglyceride-fatty acid recycling in nonobese subjects after an overnight fast and four days of starvation. Metabolism 36:251-255

24. Wolfe RR, Klein S, Carraro F, Weber J-M 1990 Role of triglyceride-fatty acid cycle in controlling fat metabolism in humans during and after exercise. Am J Physiol 258:E382-E389

25. Katz $J 1982$ Importance of sites of tracer administration and sampling in turnover studies. Fed Proc 41:123-128

26. Katz J, Okajima F, Chenoweth M, Dunn A 1981 The determination of lactate turnover in vivo with ${ }^{3} \mathrm{H}$ - and ${ }^{14} \mathrm{C}$-labelled lactate. Biochem J 194:513-524

27. Wicklmayr M, Dietze G, Rett K, Mehnert H 1985 Evidence for a substrate regulation of triglyceride lipolysis in human skeletal muscle. Horm Metab Res 17:471-475

28. Heganfeldt L, Wahren J 1968 Human forearm muscle metabolism during exercise II. Uptake, release and oxidation of individual FFA and glycerol. Scand J Clin Lab Invest 21:263-276

29. Bjorntorp P, Bergman H, Varnauskas E, Lindholm B 1969 Lipid mobilization in relation to body composition in man. Metabolism 18:841-851

30. Wolfe RR, Peters EJ, Klein S, Holland OB, Rosenblatt J, Gary Jr H 1987 Effect of short-term fasting on lipolytic responsiveness in normal and obese human subjects. Am J Physiol 252:E189-E196

31. Bortz WM, Paul P, Haff AC, Holmes WL 1972 Glycerol turnover and oxidation in man. J Clin Invest 51:1537-1546

32. Pearsall D, Palmer WK 1990 Triacylglycerol metabolism in rat skeletal muscle after exercise. J Appl Physiol 68:2451-2456

33. Marcus C, Ehren H, Bolme P, Arner P 1988 Regulation of lipolysis during the neonatal period. Importance of thyrotropin. J Clin Invest 82:1793-1797

34. Borchgrevink CF, Havel RJ 1963 Transport of glycerol in human blood. Proc Soc Exp Biol Med 113:946-949

35. Vernon RG, Walker DG 1970 Glycerol metabolism in the neonatal rat. Biochem J 118:531-536

36. Burch HB, Lowry OH, Delaney LM 1974 Enzymes of glycerol metabolism in developing rat liver and kidney. Enzyme 17:168-178

37. Ward CJ, Walker DG 1973 Regulation of enzyme development for glycerol utilization by neonatal rat liver. Biol Neonate 23:403-413

38. Hall SEH, Hall AJ, Layberry RA, Berman M, Hetenyi Jr G 1976 Effects of age and fasting on gluconeogenesis from glycerol in dogs. Am J Physiol 230:362-367

39. Winkler B, Rathgeb I, Steele R, Altszuler N 1970 Conversion of glycerol to glucose in the normal dog. Am J Physiol 219:497-502

40. Schambye P, Wood HG, Popjak G 1954 Biological asymmetry of glycerol and formation of asymmetrically labeled glucose. J Biol Chem 206:875-882

41. Swick RW, Nakao A 1954 The biological asymmetry of glycerol. J Biol Chem 206:883-886

42. Brooks BJ, Arch JRS, Newsholme EA 1983 Effect of some hormones on the rate of the triacylgylcerol/fatty acid substrate cycle in adipose tissue of the mouse in vivo. Biosci Rep 3:263-267

43. Wolfe RR, Klein S 1990 Assessment of the control of the triglyceride/fatty acid cycle. In: Chapman TE, Berger R, Reijngoud DJ, Okken A (eds) Stable Isotopes in Paediatric Nutritional and Metabolic Research. Intercept Ltd., Andover, England, pp 115-122

44. Hammond VA, Johnston DG 1987 Substrate cycling between triglyceride and fatty acid in human adipocytes. Metabolism 36:308-313

45. Wolfe RR, Herndon DN, Jahoor F, Miyoshi H, Wolfe H 1987 Effect of severe burn injury on substrate cycling by glucose and fatty acids. N Engl $\mathbf{J}$ Med 317:403-408

46. Klein S, Wolfe RR 1990 Whole-body lipolysis and triglyceride-fatty acid cycling in cachectic patients with esophageal cancer. J Clin Invest 86:1403-1408

47. Newsholme EA, Crabtree B 1976 Substrate cycles in metabolic regulation and in heat generation. Biochem Soc Symp 41:61-109 